\title{
PERAN MEDIASI STRES KERJA PADA HUBUNGAN BEBAN KERJA DENGAN KEPUASAN KERJA
}

\section{Ida Ayu Agung Hutami Pramesti ${ }^{1}$ Putu Saroyini Piartrini2}

\author{
${ }^{1,2}$ Fakultas Ekonomi dan Bisnis Universitas Udayana, Bali, Indonesia \\ email: agunghtmpramesti@gmail.com
}

\begin{abstract}
ABSTRAK
Penelitian ini bertujuan untuk mengetahui hubungan stres kerja dan beban kerja dengan kepuasan kerja dan juga mengetahui peran stress kerja dalam memediasi hubungan beban kerja dengan kepuasan kerja. Populasi dalam penelitian seluruh karyawan mantri BRI Cabang Gajah Mada Denpasar yang berjumlah 90 orang karyawan. Teknik analisis menggunakan analisis regresi linier berganda. Hasil analisis ini menunjukan bahwa beban kerja berpengaruh negative dan signifikan terhadap kepuasan keja. Stres kerja berpengaruh negatif dan signifikan terhadap kepuasn kerja. Beban kerja berpengaruh positif dan signifikan terhadap stress kerja. Hasil penelitian ini juga menunjukkan bahwa stress kerja dinilai tidak memediasi hubungan antara beban kerja terhadap kepuasan kerja karyawan. Pihak bank hendaknya perlu memperhatikan kembali komunikasi yang terjalin didalam perusahaan, waktu yang diberikan untuk mengerjakan tugas tambahan setiap hari lebih diperhatikan lagi agar karyawan tidak merasa fikirannya terkuras pada saat mengerjakan pekerjaan yang diberikan, sebaiknya pihak bank tetap menjaga standar kesehatan yang sudah diberlakukan didalam bank.
\end{abstract}

Kata kunci: beban kerja, stress kerja, kepuasan kerja

\begin{abstract}
This study aims to determine the relationship of work stress and workload with job satisfactionand also know the role of work stress in mediating the relationship of workload with job satisfaction. The population in this study were all employees of the paramedics BRI branch of Gajah Mada Denpasar, amounting to 90 employees. The analys technique uses multiple linear regression analysis. The result of the analysis show that workload has a negative and significant effect on job satisfaction. Jobstress has a negative and significant effect on job satisfaction. Workload has a positive and significan effect on work stress. The results of this study also indicate that work stres is not considered to mediate the relationship between workload and employee job satisfaction. The bank should pay attention again to the communication that is established within the company, the time given to carry out additional tasks every day more attention so that employees do not feel drained at the time of doing work given, the bank should continue to maintain the health standards that have been enforced in the bank.
\end{abstract}

Keywords: work load, job stress, job satisfaction 


\section{PENDAHULUAN}

Bank Rakyat Indonesia (Persero) Tbk yang biasa disebut dengan BRI merupakan salah satu bank milik pemerintah terbesar di Indonesia. Eksistensinya sebagai perusahaan perbankan menuntut karyawannya untuk memenuhi target yang cukup tinggi dengan standar yang tinggi untuk mencapai tujuan dari perusahaan, sehingga tidak menuntut kemungkinan adanya suatu masalah yang kerap terjadi salah satunya masalah kepuasan kerja karyawan dimana BRI memiliki jumlah karyawan yang sangat banyak diseluruh Indonesia dan khususnya di Bali. BRI cabang Gajah Mada Denpasar memiliki 17 kantor unit yang tersebar di Denpasar, antara lain terdapat di Melati, Sesetan, dan Tohpati. BRI memiliki divisi yang berperan penting dalam menjalankan perusahaan yaitu divisi mantri, divisi mantri terdapat di 17 kantor unit yang dimiliki oleh BRI cabang Gajah Mada Denpasar dengan jumlah total karyawan mantri yaitu 90 orang karyawan. Divisi mantri ini adalah divisi yang bertugas untuk menangani kredit, yang lebih sering kita dengar dengan istilah Account Officer. Berdasarkan Surat Putusan, pada BRI divisi mantri terbagi atas empat yaitu, Mantri Kupedes, Mantri Teras, Mantri Briguna, Mantri KUR. Pekerjaan yang dilakukan oleh mantri yaitu melaksanakan pemasaran produk baik itu simpan, pinjam, atau jasa bank lainnya, melakukan survei terhadap orang yang ingin meminjam kredit di BRI, melakukan analisa sebelum memberikan kredit agar pinjaman yang diberikan tepat sasaran dan aman, melakukan pembinaan terhadap nasabah terhadap nasabah agar meningkatkan dan mempertahankan kualitasaset,seta memberikan pelayanan yang prima sesuai dengan ketentuan yang berlaku untuk mencapai target yang telah ditetapkan dengan tetap berdasarkan prinsip kehati-hatian.

Peneliti melakukan studi awal terhadap lima orang karyawan mantri BRI dengan melakukan wawancara awal, hasil wawancara menunjukan bahwa kelima karyawan Mantri BRI merasa tuntukan pekerjaan yang tinggi serta susahnya mendapat promosi jabatan membuat karyawan merasa stres. Berikut adalah hasil wawancara awal dengan lima orang karyawan Mantri mengenai kepuasan kerja Bank Rakyat Indonesia Unit cabang Gaja Mada Denpasa. Nengah (nama asli disamarkan) menyatakan "Banyaknya pekerjaan yang diberikan serta kurangnya waktu dan tenaga", Ayu (nama asli disamarkan) menyatakan "Merasa lelah dalam mengerjakan pekerjaan dan susah mendapat promosi jabatan", Rina (nama asli disamarkan) menyatakan "Target yang tinggi sehingga kewalahan untuk menyelesaikan pekerjaan", Rai (nama asli disamarkan) menyatakan "Sudah sering mencapai target tetapi susah mendapatkan promosi jabatan", Bunga (nama asli disamarkan) menyatakan "Tingginya beban pekerjaan dengan standar yang tinggi".

Berdasarkan rekapitulasi hasil wawancara awal terhadap lima karyawan Mantri BRI terdapat permasalahan terhadap stres kerja tinggi berhubungan dengan beban kerja serta kepuasan kerja, sehingga penelitian ini bertujuan untuk menguji bagaimana pengaruh beban kerja terhadap kepuasan kerja karyawan BRI cabang Gajah Mada Denpasar ?; Bagaimana pengaruh stress kerja terhadap kepuasan kerja karyawan BRI cabang Gajah Mada Denpasar ?; Bagaimana pengaruh beban kerja terhadap stres kerja karyawan BRI cabang Gajah Mada Denpasar ?; Bagaimana peran stress kerja dalam memediasi pengaruh beban kerja terhadap kepuasan kerja karyawan BRI cabang Gajah Mada Denpasar?. 
Manfaat penelitian ini adalah Untuk menguji pengaruh beban kerja terhadap kepuasan kerja karyawan Mantri BRI cabang Gajah Mada, Denpasar; Untuk menguji pengaruh stres kerja terhadap kepuasan kerja karyawan Mantri BRI cabang Gajah Mada, Denpasar; Untuk menguji pengaruh beban kerja terhadap stres kerja karyawan Mantri BRI cabang Gajah Mada, Denpasar, Untuk menguji peran stress kerja dalam memediasi pengaruh beban kerja terhadap kepuasan kerja karyawan Mantri BRI cabang Gajah Mada, Denpasar.

Individu memiliki keinginan untuk memenuhi kebutuhannya, baik kebutuhan dalam berprestasi, menjalin hubungan dengan orang lain ataupun memiliki kekuasaan. Individu yang memiliki dorongan kuat untuk berhasil cenderung lebih mengejar kebutuhan yang diinginkan dari pada mengharapkan imbalan sehingga individu termotivasi untuk melakukan pekerjaannya lebih baik dan lebih efisien dibandingkan sebelumnya.

Beban kerja didefinisikan sebagai upaya untuk melakukan pekerjaan serta efisiensi dan kinerja individu. Beban kerja yang berlebih akan menyebabkan peningkatan stres, terdapat masalah mental dan juga fisik serta rasa ketidakpuasan yang mungkin menjadi ancaman terhadap kesehatan karyawan (Baheshti et.al., 2015). Turunnya produktivitas kerja dan timbulnya penyakit akibat kerja disebabkan oleh beban kerja yang sudah melebihi kapasitas. (Wahdaniyah dan miftahuddin 2018) Beban kerja merupakan proses menentukan jam kerja yang digunakan dalam menyelesaikan pekerjaan dengan jangka waktu tertentu (Setianingsih 2017). Beban kerja menurut (Akob 2016) yaitu pekerjaan yang harus diselesaikan dengan rentang waktu yang sudah ditentukan. Beban keja merupakan kegiatan yang berhubungan dengan waktu dalam hal ini dapat dilihat dari kapasitas waktu yang diberikan dalam mengerjakan suatu pekerjaan, seperti yang telah diataur dalam UU No.13 Tahun 2003 tenatang ketenagakerjaan pasal 77 ayat (2) menyatakan bahwa waktu dalam bekerja yaitu 7 jam per hari dalam satu minggu terhitung enam hari kerja atau 5 jam per hari dalam satu minggu terhitung lima hari kerja.

(Achyana 2016) menyatakan terdapat dua faktor yang memperngaruhi beban kerja yaitu faktor eksternal dan faktor internal berikut faktor eksternal merupakan pekerjaan yang bersifat fisik dan juga mental, organisai kerja, lingkungan kerja. Faktor internal yaitu factor yang berasal dari dalam diri itu sendiri. Faktor internal yaitu factor fisik dan juga psikis.

Kajian empiris mengungkapkan laporan ini sesuai dengan laporan yang ditemukan oleh (Mustapha dan Ghee 2013) manyatakan bahwa terdapat hubngan negatif signifikan antara beban kerja terhadap kepuasan kerja penelitiannya terhadap tenaga pengajar yang ada di empat universitas Klantan dengan 320 sampel. Terdapat pengaruh negatif signifikan terhadap hubungan beban kerja dan kepuasan kerja pada karyawan (Paramita et al. 2017). (Abbasi 2015) dan juga (Ariana dan Riana 2016) mengatakan beban kerja memiliki pengaruh negatif dengan kepuasan kerja. Variabel beban kerja berpengaruh negatif terhadap kepuasan kerja (Mahendrawan dan Indrawati 2015). Beban kerja memiliki pengaruh signifikan terhadap kepuasan kerja (Akhtarsha dan Selvamathi 2015). Hipotesis beban kerja terhadap kepuasan kerja dirumuskan yaitu

$\mathrm{H}_{1}$ : Beban kerja berpengaruh negatif terhadap kepuasan kerja 
Kepuasan kerja didefinisikan sebagai imbalan atas upaya karyawan dalam menyelesaikan pekerjaan yang ditargetkan dengan maksimal sehingga dapat melakukan pekerjaan dengan menikmatinya. Kepuasan kerja membuat pekerja menjadi produktif karena tingkat kepuasan kerja berperan penting bagi oganisasi atau perusahaan, organisasi atau perusahaan dapat bertahan dan sukses jika memiliki karyawan dengan tingkat kepuasan tinggi (Vasan 2018). Menurut (Utami dan Suana 2015) kepuasan kerja yang tinggi berarti seseorang tersebut memiliki perasaan positif tentang pekerjaannya, sementara seseorang yang tidak puas memiliki perasaan yang negatif tentang pekerjaan tersebut. Karyawan yang sangat puas cenderung memiliki kesehatan mental dan fisik yang baik, lebih cepat memahami pekerjaan yang diberikan, memiliki lebih sedikit kecelakaan di tempat kerja, lebih sedikit mengajukan keluhan. Menurut (Harputlu 2014) telah mengindikasikan adanya dampak dari kepuasan kerja meliputi kinerja pekerjaan, kesehatan fisik dan psikologis, burnout, komitmen berorganisasi, kepuasan hidup.

Teori dua faktor yang diungkapkan Herzberg pada penelitian (Andriani dan Widiawati 2017) mengatakan bahwah individu memiliki kebutuhan yang harus dipenuhi, individu memiliki dua kelompok kebutuhan yang diharapakan dapat diperoleh dilingkungan kerjanya yaitu pertama hygiene factor dan motivator. Hygien factors yaitu kebutuhan fisiologi individu, diharapkan dapat dipenuhi, motivators merupkan factor yang dapat memotivasi karyawan agar dapat memberikan kinerja optimal terhadap perusahaan. Hygiene factors merupakan faktor ketidakpuasan kerja meliputi kebijakan perusahaan dan administrasi, pengawasan teknis, hubungan interpersonal dengan atasan, hubungan interpersonal dengan rekan dan bawahan, gaji, keamanan kerja, kehidupan pribadi, kondisi kerja dan status. Motivators sebagai factor kepuasan kerja meliputi prestasi kerja, pengkuan, kemajuan, pekerjaan itu sendiri, adanya pertumbuhan, tanggung jawab individu (Baah dan Amoako 2011).

Kajian empiris berdasarkan teori dua faktor laporan terhadap penelitian ini sesuai terhadap laporan peneliti (Bemana et al. 2013)ayangajuga mengungkapkan adanya hubugan negatif signifikan terhadap stres kerjaadengan kepuasan kerja. (Vadivu 2016) dan (Gulavani dan Shinde, 2014) juga menemukan adanya hubungan yang signifikan pada stress kerja dengan kepuasan kerja. Stres kerja berpengaruh negatif terhadap kepuasan kerja (Mawaranti dan Prasetio 2018). Menurut (Hans et al. 2014) mengatakan adanya hubungan yang signifikan antara stress kerja dengan kepuasan kerja. Stres kerja dengan kepuasan kerja memiliki hubungan negatif menurut (Vasan 2018) dan (Ahsan et al. 2009) yang dilakukan pada Pharmaceutical sales representatis. Hipotesis stres kerja terhadap kepuasan kerja dirumuskan yaitu

$\mathrm{H}_{2}$ : Stres kerja berpengaruh negatif terhadap kepuasan kerja

Stres kerja sebagai tekanan psikologis bisa juga disebut timbulnya tekanan dari individu atau organisasi di tempat kerja, bisa diakibatkan oleh ketidak seimbangan antara kemampuan individu untuk mengatasi tuntutan pekerjaan yang diberikan menurut (Lu et al. 2015). (Adelia dan Mujiati 2016) stres yaitu perasaan tegang atau adanya tekanan emosional dalam menghadapi tuntutan yang diberikan. Menurut (Dawson et al. 2016) stres kerja dapat disebabkan adanya hubungan interpersonal yang tidak baik, hubungan antara atasan dengan bawahan, politik, 
kontrol terhadap pekerjaan, dukungan dari atasan yang tidak diterima karyawan, cemas, dan kelelahan emosional. Stres yaitu kehilangan kontrol terhadap diri sendiri akibat tidak mampu dalam menerima tekanan. Stres kerja yang tinggi dapat menyebabkan tubuh menjadi lelah sehingga dapat menurunkan tingkat kepuasan kerja (Safitri dan Astutik 2019) (Wibowo dkk. 2015) Stres.kerja juga dapat digambarkan sebagai perusakan fisik dan emosi seseorang yang muncul ketika pekerjaan yang dikerjakan tidak sejalan dengan kemampuan, sarana, atau keinginan karyawan menurut (Riaz et al. 2016). Menurut (Tantra dan Larasati 2015) stres kerja dipengaruhi oleh faktor organisasi, faktor individual, dan faktor lingkungan. Faktor organisasi terdiri tuntutan tugas, tuntutan peran, tuntutan antar pribadi, struktur organisasi dan pemimpin, faktor individual meliputi, tingkat kecemasan, kepribadian dan karakter individu dan yang sangat mengganggu yaitu masalah keluarga, masalah ekonomi pribadi, faktor lingkungan meliputi ketidak pastian ekonomi, ketidak pastian politik, dan ketidak pastian teknik.

Teori Job Demand-Resources oleh Bakker dan Demerouti yaitu tuntutan pekerjaan (job demands) yang tinggi harus sesuai dengan sumber daya pekerjaan (job resources) yang memadai. Tuntutan pekerjaan merupakan tantangan (beban kerja, tekanan waktu, tanggung jawab) dan rintangan (peran konflik, peran abiguitas) sedangkan sumber daya pekerjaan berperan penting untuk mengatasi tuntutan pekerjaan yang berlebih (Bakker dan Demerouti 2018). Job Demand merupakan tuntutan pekerjaan yang dialami oleh karyawan, tuntutan pekerjaan biasanya dapat menyebabkan stres kerja dan akan berdampak langsung terhadap tingkat produktifitas karyawan merujuk pada aspek fisik, psikologi, social dan organisasi. Job Resources pada dasarnya memudahkan karyawan dalam melakukan pekerjaan, karena Job Resources merupakan sumber daya pekerjaan merujuk pada aspek sosial dan organisasi, fisik, pekerjaan itu sendiri (Schaufeli dan Taris, 2014). Tuntutan pekerjaan yang tinggi, waktu yang kurang serta kapasitas kerja individu yang kurang memadai dapat menyebabkan stres. Sumber daya pekerjaan yang memiliki hubungan signifikansi dengan keterlibatan kerja yang sehingga tuntutan pekerjaan memiliki hubungan negatif dengan keterlibatan kerja tetapi tidak signifikan (Kamaruddin 2013).

Kajian emiris berdasarkan teori Job Demand-Resources laporan ini sesuai dengan laporan (Nurusda dkk., 2017) mengatakan.beban kerja dan setres kerja memiliki hubungan positif signifikan. (Kokoroko dan Sanda 2019) mengatakan bahwa adanya pengaruh positif antara beban kerja dengan stres kerja. (Arab et al. 2015) dan (Anggraeni 2018) mengatakan bahwa hubungan beban kerja dengan stress kerja yaitu signifikan. Menurut (Elyani dan Irmawati 2016) beban kerja berpengaruh positif terhadap tingkat stres. (Hasan dan Kurniawan 2018) mengayatakan bahwan ada hubungan positif antara beban kerja dengan stres kerja. Beban kerja berpengaruh positif terhadap stres kerja. (Susanti 2015) menyatakan bahwa beban kerja berpengaruh terhadap kepuasan kerja dengan stres kerja sebagai varibel mediasi penelitian pada guru SDN di Kecamatan Pasaman Kabupaten Pasaman Barat. Menurut penelitian (Arifani 2017) yang dilakukan pada koperasi Simpan Pinjam Mitra Raya Blimbing menyatakan bahwa stres kerja memediasi pengaruh beban kerja dengan kepuasan kerja.Stres kerja terbukti sebagai variabel mediasi dalam hubungan antara beban kerja dengan kepuasan kerja karyawan 
(Wijaya 2017). Penelitian yang dilakukan oleh (Yo dan Surya 2015) pada PT. Lianinti Abadi di Denpasar menemukan bahwa stres kerja memediasi pengaruh beban kerja terhadap kepuasan kerja. Dengan kata lain, pengaruh beban kerja terhadap kepuasan kerja sifatnya tidak secara langsung. (Madadzadeh et.al 2018) menyatakan bahwa adanya hubungan antara beban kerja dan stres kerja penelitian yang dilakukan pada perawat dirumah sakit Vasei, kota Sabzevar, Iran. Berdasarkan perspektif teori Job Demand-Resources menyatakan bahwa ketidak sesuaian tuntutan pekerjaan dengan kompetensi berakibat tingginya stres kerja.

Berdasarkan teori Job Demand-Resources dapt dirumuskanhipotesis yaitu

$\mathrm{H}_{3}$ : Beban kerjaberpengaruh positif terhadp stres kerjajk

$\mathrm{H}_{4}$ : Stres kerjamemediasi pengaruh bebankerja terhadapkepuasan kerja.

Berdasarkan kajian empiris, teori serta hipotesis yang telah dijabarkan, berikut kerangka konseptual pada Gambar 1.

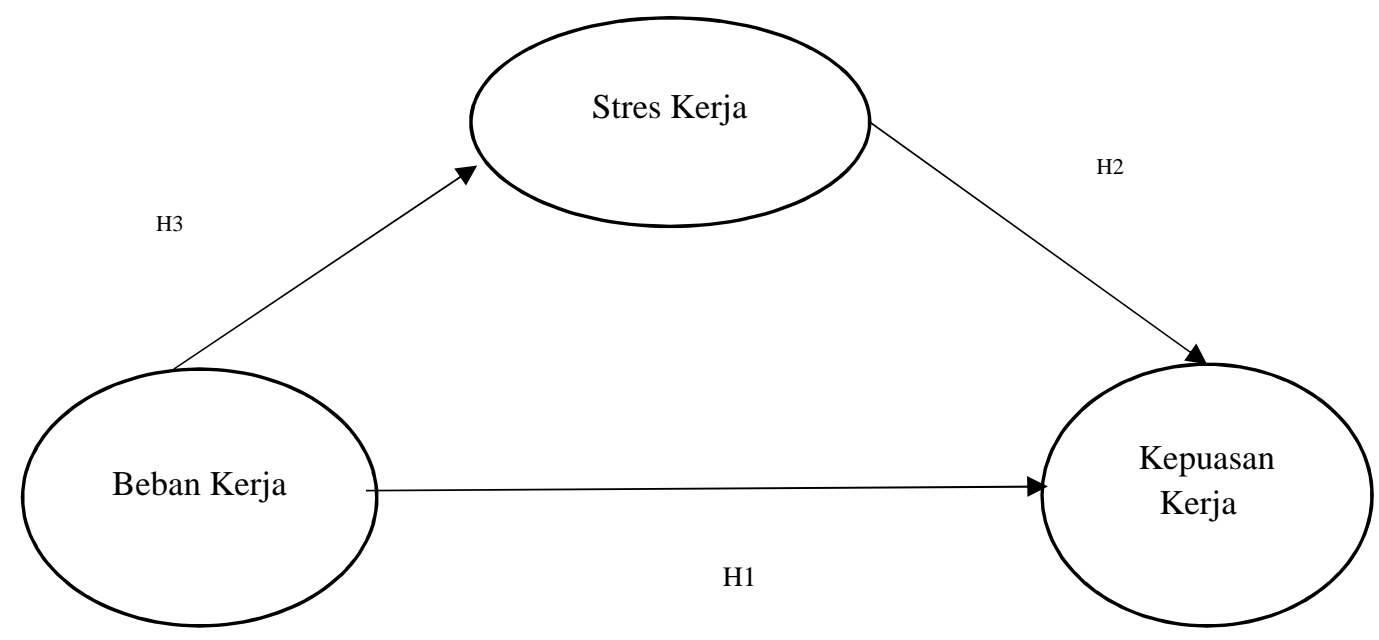

Gambar 1. Kerangka Konseptual

\section{METODE PENELITIAN}

Desain penelitian ini adalah penelitian survei yang melibatkan 90 karyawan mantri BRI cabang Gajah Mada Denpasar yang memiliki 17 kantor unit yang tersebar di Denpasar yaitu bertempat di Sudirman, Monang-maning, Gunung Agung, Renon, Kreneng, Diponegoro, Melati, Sesetan, dan Tohpati, Imam Bonjol, Sidakarya, Grenceng, Sanur, Gatot Subroto, Penatih, Tekuumar, Ubung. Obyek penelitian ini yaitu beban kerja, kepuasan kerja, dan stres kerja di Bank Rakyat Indonesia cabang Gajah Mada, Denpasar.

Difinisi operasional variabel kepuasan kerja merupakan sikap yang mencerminkan perasan seseorang terhadap pekerjaannya dengan mengharapkan adanya imbalan yang diberikan. Dimensi kepuasan kerja diadopsi menurut (Hong dan Waheed 2011) terdiri dari hygiene factor yaitu company policy, relationship 
with peer, worksecurity, relationship with supervisor, money, work condition dan motivators yaitu achievment, advancement, work it self, recognition, growth. Variabel kerpuasan kerja diukur menggunakan instrumen kepuasan kerja Spector, terdapat 13 item yang mengukur 2 dimensi dengan 11 indikator kepuasan kerja. Menggunakan alat ukur skala likert dengan interval 1 sampai dengan 5 yang mewakili interval sangat tidak setuju sampai dengan sangat tidak setuju.

Definisi operasional variabel stres kerja merupakan respon seseorang terhadap situasi yang tidak diinginkan pada fisik maupun psikologis akibat ketidak mampuan dalam mengatasi ketegangan atau tekanan karena tuntutan yang tidak seimbang dengan kapasitas kerja. Indikator stres kerja yaitu control dan support. Instrumen variabel stres kerja diukur dengan menggunakan Job Content Questionnaire oleh (Dawson et al. 2016) Job Content Questionnaire terdapat 12 item didalam mengukur indicator stres kerja. Data diukur mengunakan skalalikert dengan interval 1 sampai dengan 5 yang mewakili inteval sangat tidak setuju sampai dengan sangan tidak setuju.

Definisi operasional variabel beban kerja adalah volume kegiatan yang harus dikerjakan oleh individu dalam waktu normal setiap hari. Indikator beban kerja yaitu satisfactory, tolerable, possible, impossible. Pengukuran data variabel beban kerja menggunakan NASA-TLX yang dikembangkan oleh (Casner dan Gore 2010). NASA-TLX terdiri dari 6 item mengukur 4 indikator beban kerja. Menggunakan alat ukur skala likert dengan interva 1 sampai dengan 5 mewakil interval sangat tidak setuju sampai dengan sangat tidak setuju.

Populasi dalam penelitian ini yaitu seluruh karyawan mantri Bank Rakyat Indonesia Cabang Gajah Mada Denpasar yang berjumlah 90 orang karyawan yang terdapat pada 17 kantor unit Bank Rakyat Indonesia Cabang Gajah Mada Denpasar antara lain bertempat Sudirman, Monang-maning, Gunung Agung, Renon, Kreneng, Diponegoro, Melati, Sesetan, dan Tohpati, Imam Bonjol, Sidakarya, Grenceng, Sanur, Gatot Subroto, Penatih, Tekuumar, Ubung. Pengumpulan data tidak melibatkan prosedur dan pengambilan unit sampel karena seluruh anggota sampel menjadi unit sampel (sampel jenuh).

Data penelitian dikumpulkan berdasarkan sumber data primer dan sumber data sekunder. Sumber data primer pada penelitian ini yaitu individu karyawan mantri BRI Cabang Gajah Mada Denpasar yang terlibat sebagai narasumber, sumber data sekunder adalah jumlah karyawan mantri BRI cabang Gajah Mada Denpasar. Wawancara dan kuesioner merupakan metode penelitian yang digunakan dalam mengumpulkan data. Wawancara dilakukan untuk mengumpulkan data dengan tanya jawab secara langsung dengan karyawan mantri BRI untuk mengungkapkan gejala kepuasan kerja, beban kerja dan stres kerja. Kuesioner adalah teknik mengumpulkan data menggunakan pertanyan secara tertulis, mengacu pada instrument pengukuran data untuk mengukur tingkat kepuasan kerja, beban kerja dan stres kerja.

Hasil analisis validitas instrumen pengukuran data variabel kepuasan kerja, menunjukan hasil yang memadai dibuktikan oleh nilai parameter KMO 0.824, Barlet's test 1096.34, total variance Explaine pada bagian Eigen value, ada dua factor yang dapat terbentuk dari 13 item dianalisis. Syarat untuk menjadi sebuah faktor yaitu nilai Eigenvalue harus > 1. Nilai Eigenvalue component 1 sebesar 7.185 
$>1$ maka menjadi faktor 1 dan mampu menjelaskan $55.267 \%$ variance. Nilai Eigenvalue component 2 sebesar $2.131>1$ maka menjadi factor dan mampu menjelaskan $16.395 \%$ variance. apabila faktor dan dijumlahkan maka mampu mejelaskan $71.662 \%$ yang berarti adanya pengaruh antar item.

Hasil analisis validitas instrumen pengukuran data variabel stres kerja, menunjukan hasil yang memadai dibuktikan oleh nilai parameter KMO 0.855, Barlet's test 1092.799, total variance Explained bagian Eigen value, ada dua factor yang dapat terbentuk dari 12 item dianalisis. Syarat untuk menjadi sebuah factor yaitu nilai Eigen value harus > 1. Nilai Eigen value component 1 sebesar $6.715 \mathrm{~h}>$ 1 maka menjadi factor 1 dan mampu menjelaskan $55.959 \%$ variance. Nilai Eigenvalue component 2 sebesar $2.403>1$ maka menjadi factor 2 da $\mathrm{n}$ mampu menjelaskan $20.023 \%$ variance. Jika faktor 1 dan 2 dijumlahkan maka mampu mejelaskan $75.985 \%$ adanya pengaruh antar item.

Hasil analisis validitas instrumen pengukuran data variabl beban kerja, menunjukan hasil yang memadai dibuktikan oleh nilai parameter KMO 0.748, Barlet's test 421.492, total variance Explaine pada bagian Eigen value, ada dua factor dapat terbentuk 6 item dianalisis. Syarat menjdi factor yaitu nilai Eigen value harus $>1$. Nilai Eigenvalue component 1 sebesar 3.802>1 maka menjdi factor 1 dan mampu menjelaskan $63.359 \%$ variance. Nilai Eigenvalue component 2 sebesar $1.061>1$ menjadi factor 2 dan mampu menjelaskan $17.680 \%$ variance. Penjumlahan factor 1 dan 2 mampu menjelaskan $81.038 \%$ adanya pengaruh antar item.

Hasil uji reliabilitas yang telah dilakukan yaitu apabila nilai Crobach Alpha $>0,3$ maka instrument tersebut telah lulus uji reliabilitas atau dengan kata lain reable. Variabel kepuasan kerja memiliki nilai Cronbach Alpha sebesar 0,926. Hal ini menyatakan variabel kepuasan kerja reliabel. Variabel stress kerja memiliki nilai Cronbach Alpha yaitu 0,941. Hal ini menyatakan variabel stress kerja reliable. Variabel beban kerja memiliki nilai Cronbach Alpha sebesar 0,911 yang berarti reliabel.

Analisis jalur regresi sederhana, regresi berganda digunkan untuk menguji hipotesis penelitian ini dan metode sobel untuk mengukur peran mediasi stres kerja pada beban kerja dengan kepuasan kerja. Ujisobel yaitu menguji variabel beban kerja (X) terhadap variabel kepuasan kerja (Y) melalui variabel stress kerja (M).Tabulasi $\mathrm{Z}$ menunjukan hasil perhitungan yaitu $=-33.39$ lebih kecil dari 1,96 variabel mediator yakni stress kerja dinilai tidak dapat memediasi hubungan antara beban kerja terhadap kepuasan kerja karyawan (Utama 2016).

\section{HASIL DAN PEMBAHASAN}

Penelitian ini memiliki responden yang berjumlah 90 orang. Berdasarkan jenis kelamin, laki-laki $54 \%$ dan sisanya perempuan. Tingkat umur karyawan mantri BRI didominasi berumur 31-40 tahun. Pendidikan yang terakhir ditempuh karyawan yaitu Diploma 8.9\%, S1 86.7\%, S2 3.3\% dan sisanya S3 1.1\%. Masa kerja karyawan didominasi 6-10 tahun masa kerja dengan presentasi 38.9\%.

Distribusi skor rata-rata item indikator variabel kepuasan kerja adalah 2.66 yang artinya responden merasakan kepuasan kerja, hal ini ditunjukan dengan 
adanya dukungan dari atasan diperoleh seluruh karyawan, lokasi bekerja memiliki standar kemanan, penghargaan bagi karyawan sesuai prestasi, promosi dilakukan berdasarkan prestasi kerja, sarana kerja berfungsi dengan baik, gaji yang diterima sesuai dengan beban kerja gaji yang diterima sesuai dengan risiko kerja. Data dapat dilihat pada Tabel 1 .

Tabel 1.

Distribusi Data Responden Variabel Kepuasan Kerja

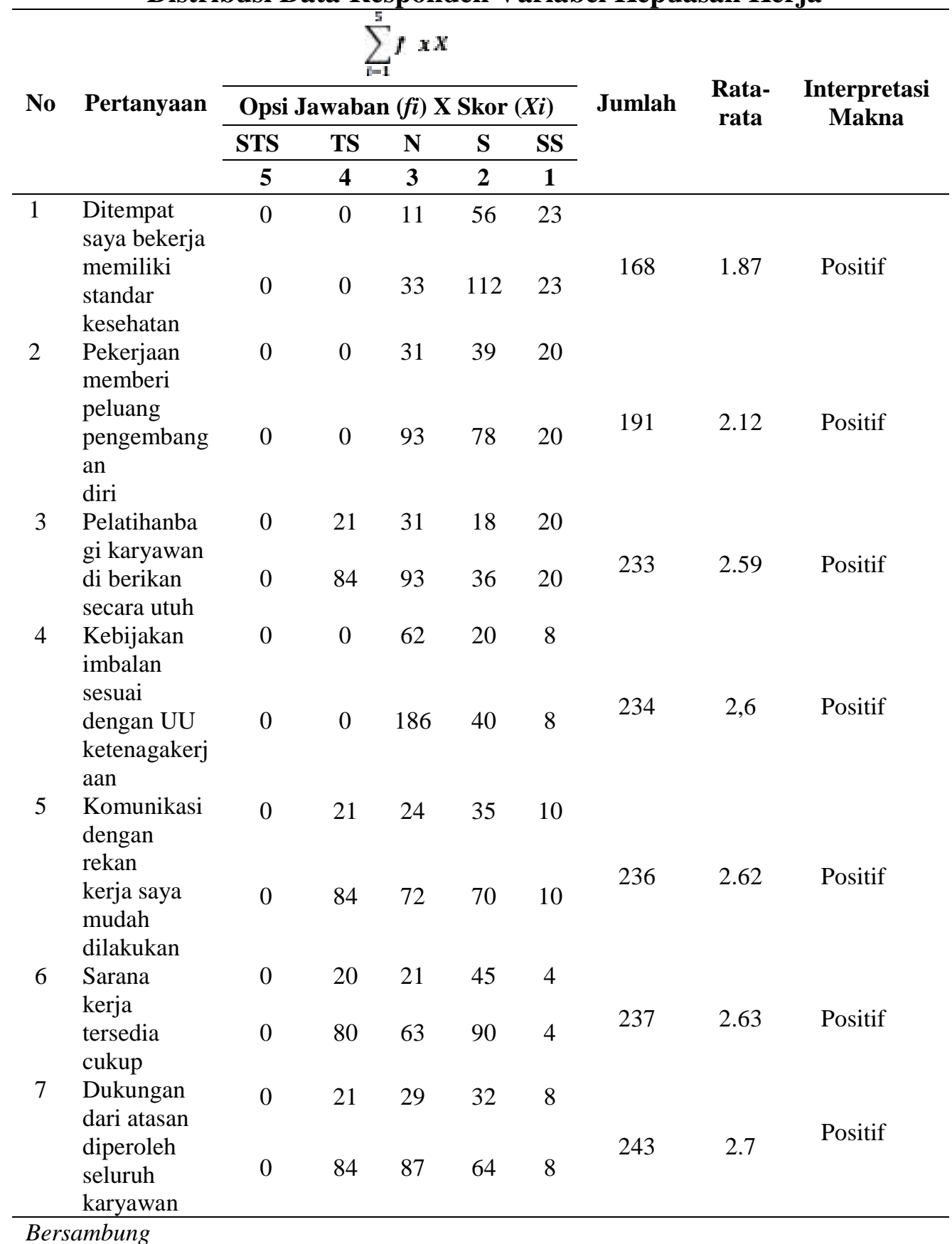


Lanjutan Tabel 1.

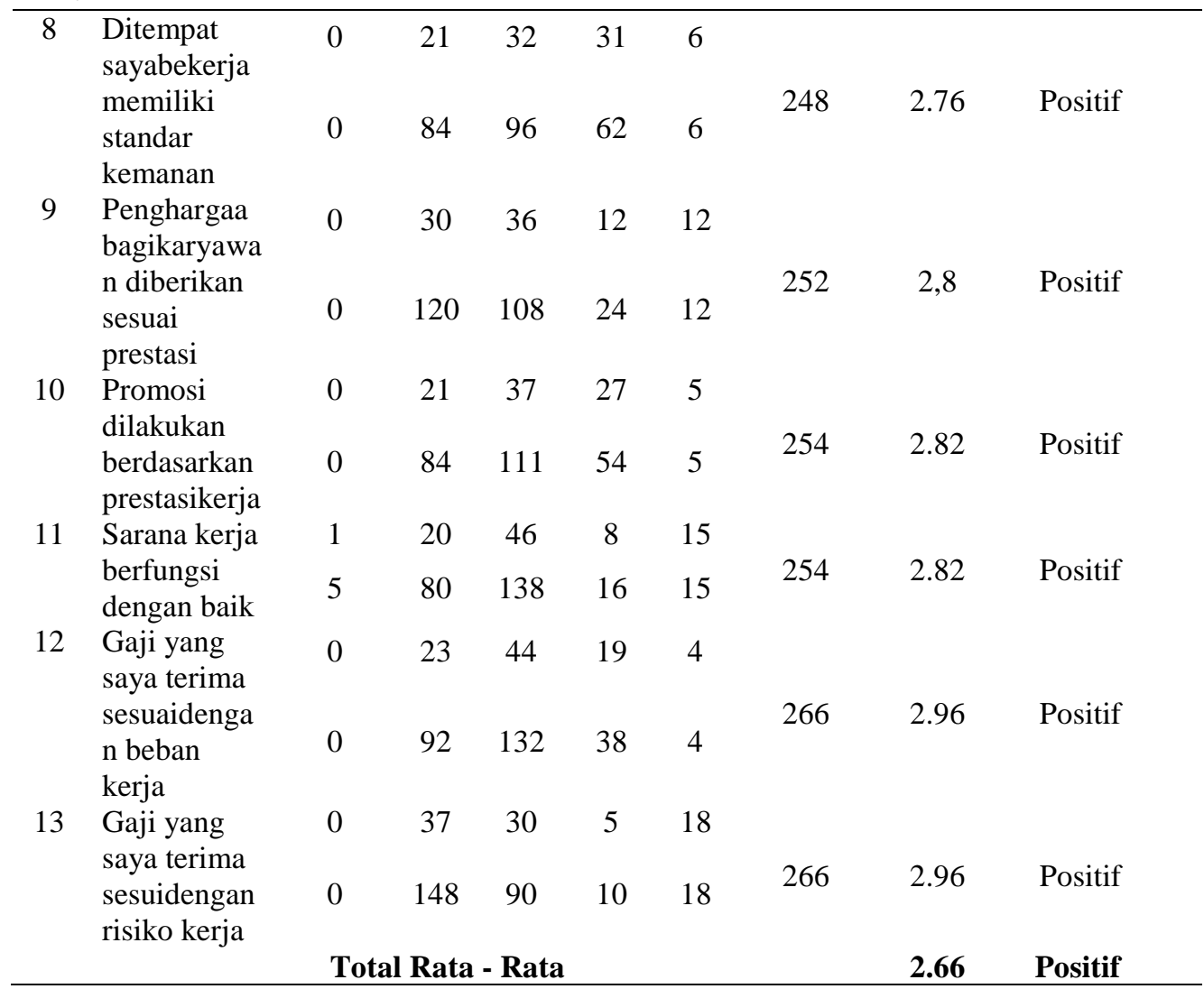

Sumber: Data diolah, 2019

Distribusi skor responden variabel stres kerja adalah 2.93 yang artinya responden merasakan stres kerja meskipun dengan intensitas yang rendah karena dapat memutuskan kapan harus melakukan pekerjaan, dapat memutuskan kapan mengakhiri waktu bekerja, keadaan ditempat kerja tidak membuat saya merasa mual meskipun keadaan ditempat kerja membuat karyawan merasa berdebar-debar, dalam organisasi individu saling menjatuhkan untuk membangun citra diri, sementara atasan cukup memberi dukungan penuh. Distribusi skor variabel stres kerja dapat dilihat pada Tabel 2 .

Distribusi skor responden indikator beban kerja menunjukan rata-rata skor 2.71 artinya responden merasakan beban kerja yang relatif tinggi, hal ini ditunjukan dengan, tidak cukup waktu untuk mengerjakan tugas rutin setiap hari, tidak mampu untuk mengerjakan tugas tambahan karena kelelahan, tidak cukup waktu untuk mengerjakan tugas tambahan dari atasan setiap hari. Skor rata-rata analisis butir indikator beban kerja dapat dilihat pada Tabel 3.

Pengujian hipotesis penelitian dilakukan dengan metode regresi berganda menunjukan bahwa pengaruh beban kerja terhadap kepuasa kerja negatif signifikan $(\beta=-0.519 ; \mathrm{t}=-5.698 ; \mathrm{p}=0.000)$. Korelasi hubungan stress kerja dengan kepuasan kerja negatif signifikan $(\beta=-0.583 ; \mathrm{t}=-6.747 ; \mathrm{p}=(0.000)$ Korelasi hubungan beban keja terhadap stres kerja positif signifikan $(\beta=0.815 ; \mathrm{t}=13.205 ; \mathrm{p}=0.000)$. 
korelasi anatara beban kerja dan stres kerja terhadap kepuasan kerja signifikan ( $\beta=$ $-0.479 ; \mathrm{t}=-0.861 ; \mathrm{p}=0.000)$.

\section{Tabel 2}

Deskripsi Data Responden Variabel Stres Kerja

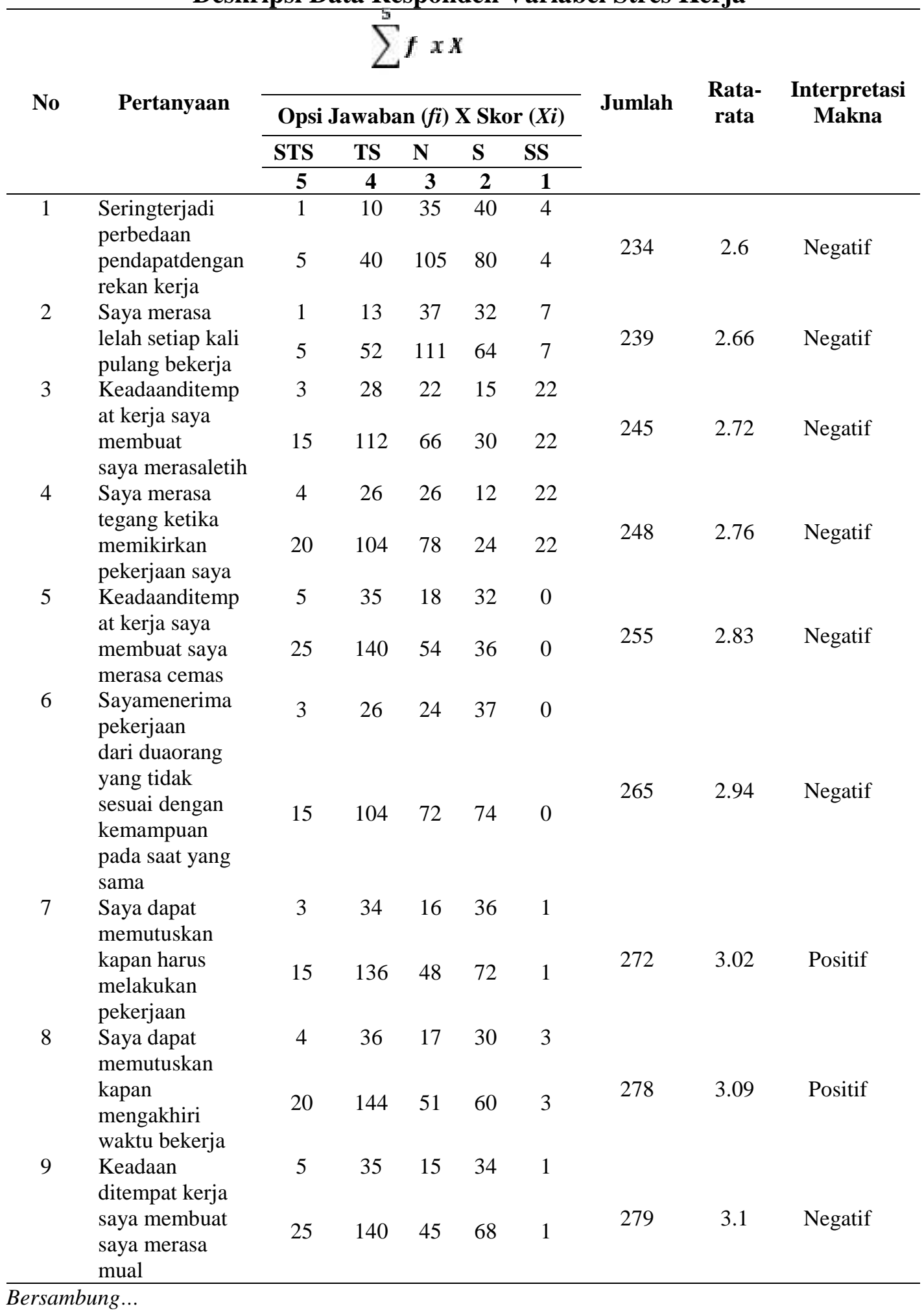




\begin{tabular}{|c|c|c|c|c|c|c|c|c|c|}
\hline & \multirow[t]{3}{*}{ Pertanyaan } & Opsi & awab & $\frac{f x}{\ln (f i)}$ & Sk & $(X i)$ & \multirow[t]{3}{*}{ Jumlah } & & \\
\hline \multirow{2}{*}{ No } & & STS & TS & $\mathbf{N}$ & $\mathbf{S}$ & SS & & \multirow{2}{*}{$\begin{array}{l}\text { Rata- } \\
\text { rata }\end{array}$} & \multirow{2}{*}{$\begin{array}{c}\text { Interpretasi } \\
\text { Makna }\end{array}$} \\
\hline & & 5 & 4 & 3 & 2 & 1 & & & \\
\hline \multirow[t]{2}{*}{10} & $\begin{array}{l}\text { Keadaanditemp } \\
\text { at kerjasaya }\end{array}$ & 6 & 35 & 14 & 34 & 1 & & & \\
\hline & $\begin{array}{l}\text { membuat } \\
\text { saya merasa } \\
\text { berdebar-debar }\end{array}$ & 30 & 140 & 42 & 68 & 1 & 281 & 3.12 & Negatif \\
\hline \multirow[t]{2}{*}{11} & Orang - orang & 8 & 29 & 38 & 15 & 0 & & & \\
\hline & $\begin{array}{l}\text { menjatuhkan } \\
\text { orang lainuntuk } \\
\text { membangun } \\
\text { citra diri }\end{array}$ & 40 & 116 & 114 & 30 & 0 & 300 & 3.33 & Negatif \\
\hline \multirow[t]{3}{*}{12} & Dukungan & 6 & 52 & 20 & 11 & 1 & & & \\
\hline & $\begin{array}{l}\text { dari atasantidak } \\
\text { diperoleh }\end{array}$ & 30 & 208 & 60 & 22 & 1 & 321 & 3.57 & Negatif \\
\hline & \multicolumn{6}{|c|}{ Total Rata - Rata } & & 2.93 & Negatif \\
\hline
\end{tabular}

Tabel 3.

Distribusi Data Responden Variabel Beban Kerja

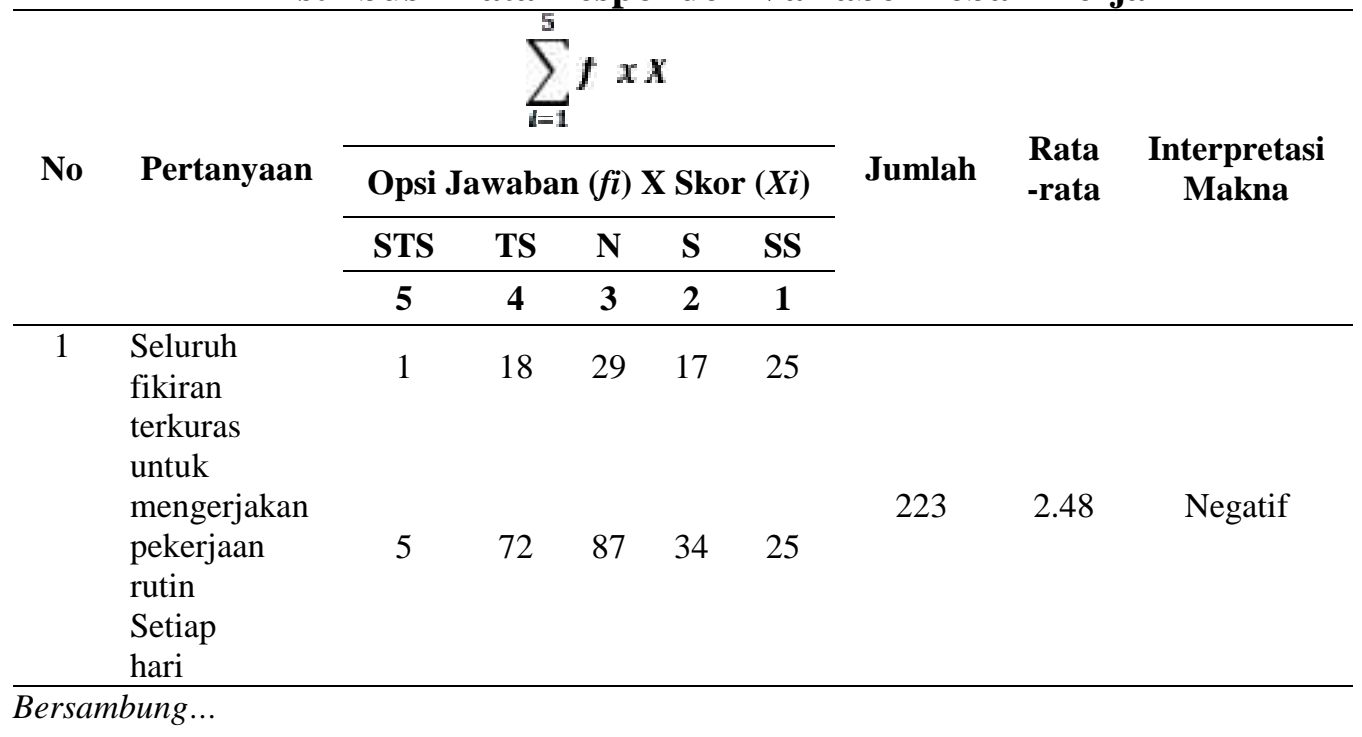


Lanjutan Tabel 3.

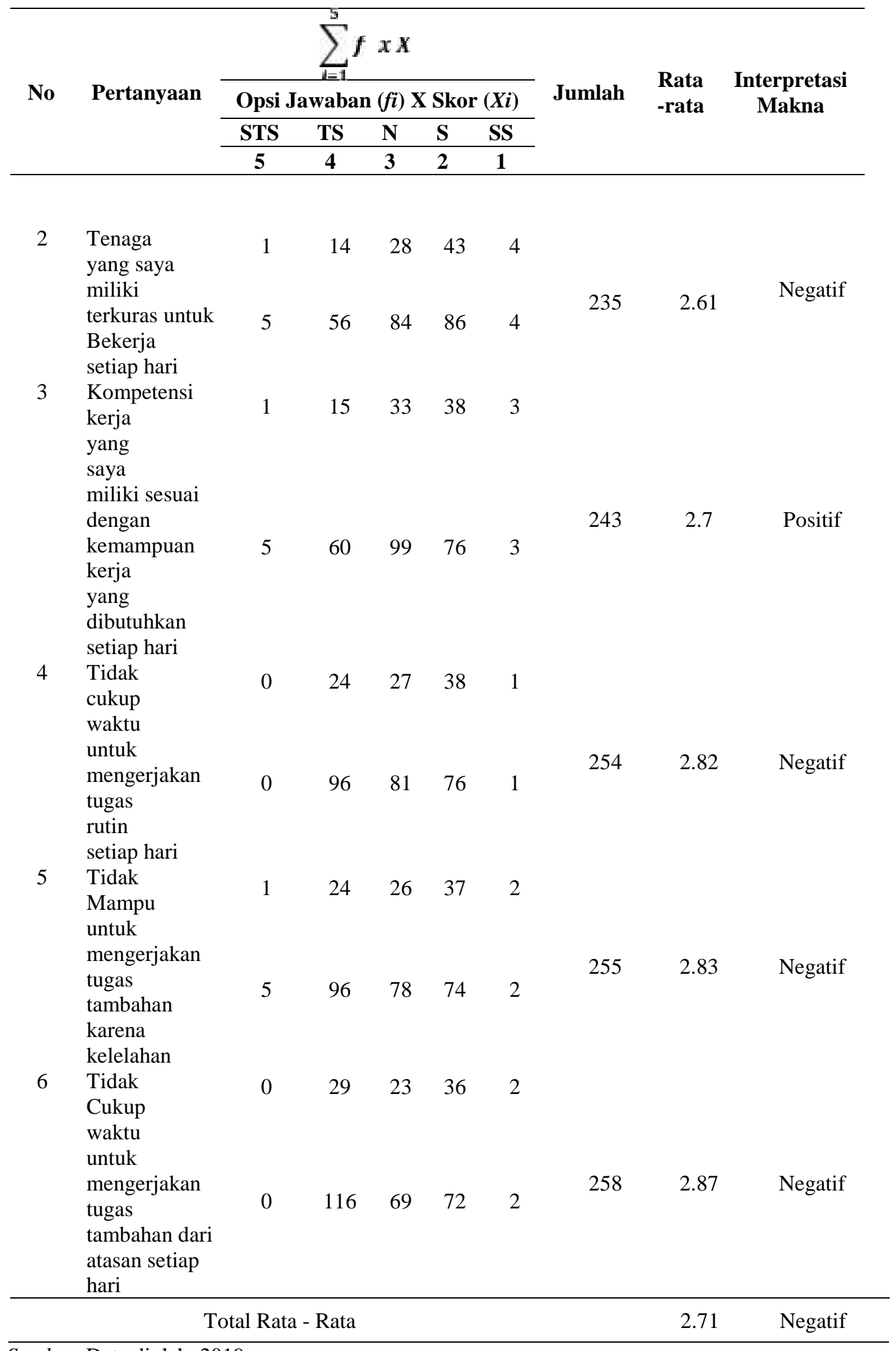


Respon karyawan mantri BRI Cabang Gajah Mada Denpasar terhadap aspek beban kerja dan kepuasan kerja menjelaskan yaitu variabel bebankerja berkorelasi dengan kepuasan kerja, sehingga penelitian ini sesuai dengan laporan yang ditemukan oleh Menurut (Mustapha and Ghee 2013) manyatakan bahwa ada hubungan negatif signifikan antara beban kerja dengan kepuasan kerja penelitiannya terhadap tenaga pengajar yang ada di empat universitas Klantan dengan 320 sampel. Beban kerja mempunyai pengaruh negative dan signifikan terhadap kepuasan kerja pada karyawan (Paramita et al. 2017). (Abbasi 2015) adanya pengaruh negatif antara beban kerja dengan kepuasan kerja. Variabel beban kerja berpengaruh negatif terhadap kepuasan kerja (Mahendrawan and Indrawati 2015) Beban kerja memiliki pengaruh signifikan dengan kepuasan kerja (Akhtarsha dan Selvamathi 2015) Berdasarkan hasil analisis data deskriptif beban kerja yaitu kemampuan kerja individu sudah memenuhi kompetensi yang ada tetapi waktu yang diberikan tidak cukup untuk mengerjakan tugas sehari-hari dan tugas tambahan, pada kepuasan kerja meskipun imbalan yang diberikan sudah sesuai dengan UU ketenagakerjaan tetapi gaji yang diberikan belum sesuai dengan beban dan resiko kerja yang diterima individu.

Hasil analisis data menyatakan bahwa pada beban kerja "Seluruh fikiran terkuras untuk mengerjakan pekerjaan rutin setiap hari” dengan nilai rata-rata 2.48 dengan nilai dibawah total rata-rata yaitu 2.71 yang artinya benar karyawan merasakan seluruh fikirannya terkuras pada saat mengerjakan pekerjaan rutin, kemudian pada kepuasan kerja "Ditempat saya bekerja memiliki standar kesehatan" dengan nilai rata-rata 1.87 lebih kecil dari total rata-rata yaitu 2.66 yang artinya karyawan merasa puas dengan standar kesehatan yang diberikan perusahaan. Hal ini membuktikan bahwa benar karyawan merasakan beban kerja tetapi tetap merasakan kepuasan kerja.

Respon karyawan mantri BRI Cabang Gajah Mada Denpasar terhadap aspek stress kerja dan kepuasan.kerja menunjukan bahwa stress kerja berkorelasi dengan kepuasan kerja, penelitian serupa dengan laporan penelitian (Bemana et al. 2013) mengungkapkan bahwa stress kerja dengan kepuasan memiliki hubungan negatif signifikan. (Vadivu 2016) dan (Gulavani dan Shinde, 2014) juga mengatakan adanya hubungan signifikan antara stres kerja dengan kepuasan kerja. Menurut (Hans et al. 2014) adanya hubungan signifikan antara stres kerja dengan kepuasan kerja. Menurut (Harputlu 2014) telah mengindikasikan adanya dampak dari kepuasan kerja meliputi kinerja pekerjaan, kesehatan fisik dan psikologis, burnout, komitmen berorganisasi, kepuasan hidup. Stres keja dengan kepuasan kerja memiliki hubungan negative signifikan menurut (Vasan, 2018) yang dilakukan pada Pharmaceutical sales representatis. Berdasarkan hasil analisis data deskriptif menyatakan pada stress kerja meskipun individu dapat mengatur waktu untuk memulai dan mengakhiri pekerjaan tetapi perilaku lingkungan kerja tidak kondusif karena untuk membangan citra diri individu saling menjatuhkan satu sama lain, pada kepuasan kerja imbalan yang diberikan sudah sesuai dengan UU ketenaga kerjaan tetapi gaji yang diberikan belum sesuai dengan beban dan resiko kerja yang diterima individu. (Ahsan et al. 2009) tentang studi hubungan antara stres kerja 
dengan kepuasan kerja pada staf universitas di Malaysia menyatakan bahwa adanya hubungan negatif signifikan antara stres kerja dengan kepuasan kerja.

Hasil analisis data menyatakan bahwa pada stres kerja "sering terjadi perdebatan pendapat dengan rekan kerja" dengan nilai rata-rata 2.6 lebih kecil dari jumlah total rata-rata yaitu 2.93 yang artinya karyawan benar merasakan seringnya terjadi perbedaan pendapat dengan rekan kerja, kemudian pada kepuasan kerja "Ditempat saya bekerja memiliki standar kesehatan" dengan nilai rata-rata 1.87 lebih kecil dari total rata-rata yaitu 2.66 yang artinya karyawan merasa puas dengan standar kesehatan yang diberikan perusahaan. Hal ini menyatakan bahwa benar karyawan merasakan stres kerja tetapi tidak merasakan ketidakpuasan kerja.

Respon karyawan mantri BRI Cabang Gajah Mada Denpasar terhadap aspek beban kerja dan stress kerja menunjukan bahwa beban kerja berkorelasi postif dengan stres kerja. Hasil penelitian ini tidak berbeda dengan temuan yang dilaporkan oleh (Nurusda dkk. 2017) menyatakan bahwa adanya hubungan positif signifikan antara beban kerja dengan stres kerja. (Kokoroko dan Sanda 2019) menemukan bahwa ada pengaruh positif antara beban kerja terhadap stress kerja. (Arab et al. 2015) dan (Anggraeni 2018) menyatakan beban kerja berpengaruh signifikan stres kerja. Menurut (Elyani dan Irmawati 2016) beban kerja berpengaruh positif terhadap tingkat stress pada seluruh perawat Instalansi Diagnostik Intervensi Kardiovaskular. (Hasan dan Kurniawan 2018) mengayatakan bahwan ada hubungan positif antara beban kerja dengan stres kerja, beban kerja berpengaruh positif terhadap stres. (Susanti 2015) menyatakan bahwa beban kerja berpengaruh terhadap kepuasan kerja dengan stress kerja sebagai varibel mediasi penelitian pada guru SDN di Kecamatan Pasaman Kabupaten Pasaman Barat. Hubungan beban kerja dengan stress kerja yaitu positif menurut (Madadzadeh et al. 2018) menyatakan bahwa adanya hubungan antara beban kerja dan stres kerja pada dirumah sakit Vasei, kota Sabzevar, Iran. Berdasarkan perspektif teori Job Demand - Resources menyatakan bahwa ketidak sesuaian tuntutan pekerjaan dengan kompetensi berakibat tingginya stress kerja. Berdasakan hasil analisis data deskriptif menyatakan bahwa pada beban kerja meskipun kemampuan kerja sudah memenuhi kompetensi yang ada tetapi waktu yang diberikan tidak cukup untuk mengerjakan tugas sehari-hari dan tugas tambahan, pada stres kerja meskipun individu dapat mengatur waktu untuk memulai dan mengakhiri pekerjaan tetapi perilaku lingkungan kerja tidak kondusif karena untuk membangun citra diri individu saling menjatuhkan satu sama lain.

Hasil analisis data menyatakan bahwa pada stres kerja "sering terjadi perdebatan pendapat dengan rekan kerja" dengan nilai rata-rata 2.6 yang berarti karyawan menyatakan bahwa benar sering terjadi perbedaan pendapat dengan rekan kerja kemudian pada beban kerja "Seluruh fikiran terkuras untuk mengerjakan pekerjaan rutin setiap hari" dengan nilai rata-rata 2.48 yang berarti karyawan merasa fikirannya terkuras untuk mengerjakan tugas rutin setiap harinya. Hal ini menyatakan bahwa benar karyawan merasakan stres kerja dan juga beban kerja terhadap pekerjaan yang diberikan.

Hasil uji sobel didapatkan yaitu stresskerja tidak dapat memediasi pengaruh beban kerja terhadap kepuasan kerja, sehingga dapat dikatakan bahwa stres kerja tidak dapat memediasi pengaruh beban kerja terhadap kepuasan kerja.Penelitian 
sejalan dengan penelitian yang dilaporkan oleh (Aprilia 2018) menyatakan bahwa stress kerja tidak dapat dijadikan pemediasi terhadap hubungan bebankerja dengan kepuasankerja. Menurut( Zaidan 2018) stress kerja kerja tidak dapat memediasi hubungan beban kerja terhadap kepuasan kerja berdasarkan penelitian terhadap dosen Universitas Negeri Malang. Karyawan yang marasakan stres kerja yang tinggi dengan tingkat beban kerja yang tinggi belum tentu merasakan ketidakpuasan dalam pekerjaannya. Menurut penelitian (Arifani 2017) yang dilakukan pada koperasi Simpan Pinjam Mitra Raya Blimbing menyatakan bahwa stres kerja memediasi pengaruh beban kerja dengan kepuasan kerja.Stres kerja terbukti sebagai variabel mediasi dalam hubungan antara beban kerja dengan kepuasan kerja karyawan (Wijaya 2017). Penelitian yang dilakukan oleh (Yo dan Surya 2015) pada PT. Lianinti Abadi di Denpasar menemukan bahwa stres kerja memediasi pengaruh beban kerja terhadap kepuasan kerja. Dengan kata lain, pengaruh beban kerja terhadap kepuasan kerja sifatnya tidak secara langsung.

Karyawan yang marasakan stres kerja yang tinggi dengan tingkat beban kerja yang tinggi belum tentu merasakan ketidakpuasan dalam pekerjaannya. Hasil analisis data menyatakan pada stres kerja "sering terjadi perdebatan pendapat dengan rekan kerja" dengan nilai rata-rata 2.6 yang berarti karyawan menyatakan bahwa benar sering terjadi perbedaan pendapat dengan rekan kerja, pada beban kerja "Seluruh fikiran terkuras untuk mengerjakan pekerjaan rutin setiap hari" dengan nilai rata-rata 2.48 . Hal ini berarti karyawan merasa fikirannya terkuras untuk mengerjakan tugas rutin setiap harinya, kemudian pada kepuasan kerja "Ditempat saya bekerja memiliki standar kesehatan" dengan nilai rata-rata 1.87 yang artinya karyawan menyatakan bahwa didalam perusahaan memiliki standar kesehatan sehingga karyawan merasakan kepuasan kerja.

BRI cabang Gajah Mada, Denpasar diharapkan melakukan perhatian terhadap karyawan BRI dengan memperhatikan waktu kerja yangediberikan kepada karyawan, lingkungankerja agar dibuat lebihkondusif serta gaji dapat diberikan sebaiknya disesuaikan kembali, sehingga kepuasan kerja meningkat karena kalau tidak dikelola berakibat adanya intensi kerluar.

\section{SIMPULAN}

Beban kerja memiliki pengaruh negatif dan signifikan terhadap kepuasan kerja. Hal ini menunjukan bahwa semakin tinggi tingkat beban kerja belum tentu tingkat kepuasan kerjanya rendah. Stres kerja memiliki pengaruh negatif dan signifikan terhadap kepuasan kerja. Hal ini menunjukan bahwa semakin tinggi tingkat stres kerja belum tentu tingkat kepuasan kerjanya rendah. Beban kerja berpengaruh positif signifikan terhadap stress kerja. Hal ini menunjukan apabila semakin tinggi tingkat beban kerja semakin tinggi tingkat stress kerja karyawan terhadap perusahaan tersebut. Stres kerja dinilai tidak dapat memediasi hubungan antara beban kerja terhadap kepuasan kerja karyawan.

Rekomendasi terhadap pihak bank hendaknya diharapkan memberikan perhatikan kepada karyawan bidang mantri, kebijakan penilaian kinerja dibuat lebih transparan sehingga perilaku politik individu dapat diminimalkan dan perbedaan pendapat dikurangi. Pihak bank hendaknya perlu memperhatikan kembali 
komunikasi yang terjalin didalam perusahaan misalnya dalam perbedaan pendapat dengan sesama rekan kerja apabila hal ini sering terjadi karyawan akan merasa stres, waktu yang diberikan untuk mengerjakan tugas tambahan setiap hari lebih diperhatikan lagi agar karyawan tidak merasa fikirannya terkuras pada saat mengerjakan pekerjaan yang diberikan karena apabila karyawan merasa fikirannya terkuran karyawan akan merasa lelah dan terkahir untuk menjaga kepuasan karyawan sebaiknya pihak bank mempertahan kepuasan yang sudah diterima oleh karyawan misalnya tetap menjaga standar kesehatan yang sudah diberlakukan didalam bank.

Peneliti selanjutnya, responden karyawan Bank Rakyat Indonesia cabang Gajah Mada Denpasar pada jabatan mantri dilakukan replikasi dengan melibatkan pemegang jabatan staf admin, kasir ataupun Customer Service untuk menguji konsistensi temuan. Manajemen mengkaji aspek transparan system penilaian kinerja dengan pola interaksi atasan dengan bawahan untuk meminimalkan perilaku politik individu. Hal ini diupayakan agar dapat diperoleh indikator yang lebih mendekati dengan teori-teori yang di teliti agar dapat lebih melengkapi penelitian ini. Penelitian selanjutnya juga diharapkan untuk menggunakan variabel lain, karena masih banyak variabel-variabel lain dapat mempengaruhi kepuasan kerja karyawan.

\section{REFERENSI}

Abbasi, T. F. 2015. Impact of Work Overload on Stress, Job Satisfaction, and Turnover Intentions with Moderating Role of Islamic Work Ethics. Management Studies and Economic Systems 2(1):27-37.

Achyana, M. 2016. Faktor-Faktor Yang Mempengaruhi Beban Kerja Room Attendant Di Grand Jatra Hotel Pekan Baru. 3(2):368.

Adelia, A. A. S. R. C., \& Mujiati, N. W. 2016. Pengaruh Kompensasi, Gaya Kepemimpinan Dan Stres Kerja Terhadap Kepuasan Kerja Karyawan Di Rumah Sakit Dharma Kerti. 5(6):246852.

Ahsan, N., Z. Abdullah, D. Y. G., Fie, S. S. \& Alam. 2009. A Study of Job Stress on Job Satisfaction among University Staff in Malaysia: Empirical Study. European Journal of Social Sciences 8(1):121-31.

Aktharsha, S. U., \& Selvamathi, A. 2015. Job Stres and Job Satisfaction: an Study Among Nursing Personnel in Hospitals. International Journal of Management. 6(1). 385-393.

Akob, M. 2016. Influence Workload, Work Ethic and Job Satisfaction toward Teacher's Performance (Study of Islamic-Based School in MakasarIndonesia). Global Advanced Research Journals of Management and Business Studies 5(7):172-77.

Andriani, M., \& Widiawati, K. 2017. Penerapan Motivasi Karyawan Menurut Teori Dua Faktor Frederick Herzberg Pada PT Aristika Kreasi Mandiri. Jurnal Administrasi Kantor 5(1):83-98.

Anggraeni, K. 2018. Analisis Pengaruh Beban Kerja Terhadap Kepuasan Kerja 
Dengan Stres Kerja Sebagai Variabel Intervening.

Aprilia, B. N. 2018. Pengaruh Beban Kerja Terhadap Kepuasan Kerja Dengan Stres Kerja Sebagai Variabel Intervening (Studi Kasus Pada Karyawan Rumah Sakit Kasih Ibu Surakarta).

Arab, Z., Piri, L. N., Arsalani, T. G. F, \& Biglarian, A. 2015. The Correlation of Workload and Work Ability with Job Stress in Nursing Staff. Journal of Health Promotion Management (Jhpm) 4(1):54-65.

Ariana, I. W. J., \& Riana, I. G. 2016. Pengaruh Work-Family Conflict, Keterlibatan Kerja Dan Stres Kerja Terhadap Kepuasan Kerja Karyawan. E-Jurnal Manajemen Universitas Udayana 5(7):255105.

Arifani, E. 2017. Pengaruh Beban Kerja Terhadap Kepuasan Kerja Dengan Stres Kerja Sebagai Variabel Mediasi Pada Koperasi Simpan Pinjam Mitra Raya Blimbing.

Baah, K. D., \& Amoako, G. K. 2011. Application of Frederick Herzberg' s Two Factor Theory in Assessing and Understanding Employee Motivation at Work: A Ghanaian Perspective. European Journal of Business and Management 3(9):1-9.

Bakker, A. B., \& Demerouti, E. 2018. Multiple Levels in Job Demands - Resources Theory : Implications for Employee Well-Being and Performance. Handbook of Well-Being (2018):1-13.

Bemana, S., Moradi, H., Ghasemi, M., Taghavi, S. M., \& Ghayoor, A. H. 2013. The Relationship among Job Stress and Job Satisfaction in Municipality Personnel in Iran. World Applied Sciences Journal 22(2):233-38.

Casner, S. M., \& Gore, B. F. 2010. Measuring and Evaluating Workload: A Primer. NASA Technical Memorandum (2010-216395).

Dawson, K. M., O'Brien, K. E. \& Beehr, T. A. 2016. The Role of Hindrance Stressors in the Job Demand-Control-Support Model of Occupational Stress: A Proposed Theory Revision. Journal of Organizational Behavior 37(3):397-415.

Elyani, N., \& Irmawati. L. I. 2016. Analisis Tingkat Beban Kerja Terhadap Stres Kerja Perawat Di Instalasi Diagnostik Intervensi Kardiovaskular Rsud Dr. Soetomo. Jurnal Manajemen Kesehatan Yayasan RS.Dr. Soetomo 2(2):133.

Hans, A., Mubeen, S. A., Sultan, K., \& Saadi. A. S. M. A. 2014. A Study on Work Stress and Job Satisfaction among Headmasters: A Case Study of Bilingual Schools in Sultanate of Oman - Muscat. Journal of Sociological Research 5(1):40.

Harputlu, S. 2014. Job Satisfaction and Relation With Perceived Workload: An Application in A Research Institution.

Hasan, A., Wahyuni, I., \& Kurniawa, B. 2018. Hubungan antara Beban Kerja Mental dan Shift Kerja terhadap Stres Kerja pada Pekerja Central Control Room (Studi Kasus pada PT. PJB Unit Pembangkit Paiton Probolinggo). 
Jurnal Kesehatan Masyarakat. 6(4). 255-260.

Hong, T. T., \& Waheed, A. 2011. Herzberg's Motivation-Hygiene Theory and Job Satisfaction in the Malaysian Retail Sector: The Mediating Effect of Love of Money. Asian Academy of Management Journal 16(1):0-33.

Kamaruddin, R. B. 2013. Relationship Between Job Demand and Job Resources on Employees Work Engagement in HVAC Industry in Malaysia.

Kokoroko, E., \& Sanda, M. A. 2019. Effect of Workload on Job Stress of Ghanaian OPD Nurses: The Role of Coworker Support. Safety and Health at Work 10(3):341-46.

Lu, L., Liu, L., Sui, G., \& Wang, L. 2015. The Associations of Job Stress and Organizational Identification with Job Satisfaction among Chinese Police Officers: The Mediating Role of Psychological Capital. International Journal of Environmental Research and Public Health 12(12):15088-99.

Madadzadeh, M., Barati, H., \& Asour, A. A. 2018. The Association between Workload and Job Stress among Nurses in Vasei Hospital, Sabzevar City, Iran, in 2016. Journal of Occupational Health and Epidemiology 7(2):83-89.

Mahendrawan, I. G., \& Indrawati, A. D. 2015. Pengaruh Beban Kerja Dan Kompensasi Terhadap Kepuasan Kerja Pt. Panca Dewata Denpasar. E-Jurnal Manajemen Universitas Udayana 4(11):250973.

Mawaranti, R., \& Prasetio, A. P. 2018. Dampak Stres Kerja Terhadap Kepuasan Kerja. Jrmb 13(1):37-45.

Mustapha, N., \& W. Y. Ghee. 2013. "Examining Faculty Workload as a Single Antecedent of Job Satisfaction among Higher Public Education Staff in Kelantan, Malaysia." Business and Management Horizons 1(1):10.

Nurusda, E., Akmal, \& Kamelia, I. 2017. Pengaruh Lingkungan Kerja Dan Beban Kerja Terhadap Stres Kerja Pada Karyawan PT. Perkebunan Teh Nusantara VI. Jurnal Bunghatta 10(2):45-57.

Paramita, W., Pambudi, W. S., \& Aminah, H. 2017. The Impact of Career Development and Workload Toward Employee Job Satisfaction At Pt Askrindo Jakarta. JRMSI - Jurnal Riset Manajemen Sains Indonesia 8(1):39.

Riaz, M., Ahmad, N., Riaz, M., Murtaza, G., Khan, T., \& Firdous , H. 2016. Impact of Job Stress on Employee Job Satisfaction. International Review of Management and Business Research 5:4.

Safitri, L. N., \& Astutik, M. 2019. Pengaruh Beban Kerja Terhadap Kepuasan Kerja Perawat Dengan Mediasi Stress Kerja. JMD: Jurnal Riset Manajemen \& Bisnis Dewantara 2(1):13-26.

Schaufeli, W, B., \& Taris, T. W. 2014. A Critical Review of the Job Deman Resources Model: Implications for Improving Work and Health. Springer Science Business Media Dordrecht. 43-68.

Setianingsih, A. 2017. Beban Kerja Dan Motivasi Terhadap Kepuasan Pegawai PNS Dan Non-PNS. Jurnal Ilmu Kesehatan Masyarakat 6(04):171-79. 
Susanti, N. 2015. Pengaruh Karakteristik Individu Dan Beban Kerja Guru Terhadap Kepuasan Kerja Dengan Stres Kerja Sebagai Variabel Intervening.

Tantra, S., \& Larasati, T. 2015. Faktor-Faktor Sosial Yang Mempengaruhi Stres Kerja Social Factors Affecting Job Stress. Jurnal Majority 4(9):58-63.

Utama, Made Suyana. 2016. Aplikasi Analisis Kuantitatif Untuk Ekonomi Dan Bisnis.

Utami, A. A. S. D. P., \& Suana , I. W. 2015. Pengaruh Kepemimpinan Transaksional Dan Stres Kerja Terhadap Kepuasan Kerja Karyawan Pada Pt. Pln (Persero) Area Bali Selatan. E-Jurnal Manajemen Universitas Udayana 4(3):254753.

Vadivu, T. S. 2016. A Study on Occupational Stress and Job Satisfaction. International Journal of Business Innovation and Research 11(3):417-30.

Vasan, M. 2018. Impact of Job Stress on Job Satisfaction among the Pharmaceutical Sales Representatives. Research Journal of Pharmacy and Technology 11(9):3759-64.

Wahdaniyah, N., \& Miftahuddin. 2018. Pengaruh Hardiness, Beban Kerja, Dan Faktor Demografi Terhadap Stres Kerja Guru. 6(1):69-84.

Wibowo, I. G. P., Riana, G., \& Putra, M. S. 2015. Pengaruh Stres Kerja Terhadap Kepuasan Kerja Dan Komitmen Organisasional Karyawan. Jurnal Ekonomi Dan Bisnis 02:125-45.

Wijaya, A. 2017. Pengaruh Beban Kerja Terhadap Kepuasan Kerja. Parsimonia ISSN 2355-5483 4(3):278-88.

Yo, P. M. P \& Surya, I. B. K. 2015. Pengaruh Beban Kerja Terhadap Kepuasan Kerja Dengan Stres Kerja Sebagai Variabel Mediasi. E-Jurnal Manajemen Universitas Udayana 4(5):254-931.

Zaidan, A. F. 2018. Pengaruh beban kerja Terhadap kepuasan kerja dosen universitas negeri malang melalui stres kerja sebagai variabel intervening. 